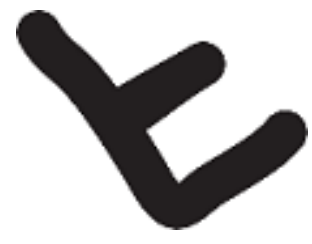

REVISTA DE ESTUDIOS E INVESTIGACIÓN

EN PSICOLOGÍA Y EDUCACIÓN

ISSN: 1138-1663; eISSN: 2386-7418

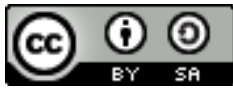

2016, Vol. 3, No. 2, 131-139. DOI: 10.17979/reipe.2016.3.2.1903

\title{
Effects of a voice recognition system on phonological awareness and reading skills in Spanish preschool children
}

\author{
Efectos de un sistema de reconocimiento de voz en la conciencia fonológica y las \\ habilidades de lectura de niños preescolares españoles
}

\begin{abstract}
María-Luz Fernández-Amado*, Alejandro Tuñas-García**, Manuel Peralbo-Uzquiano***, María A. Mayor-Cinca****, Begoña Zubiauz de Pedro****, Manuel García-Fernández****

*San Juan Bosco School (A Coruña- Spain), **ALTIA S.L. (A Coruña- Spain), ***Faculty of Education. University of A Coruña (A Coruña- Spain), ****Faculty of Psychology. University of Salamanca (Salamanca- Spain)
\end{abstract}

\begin{abstract}
The main aim of this research is to analyse the effects of a Voice Recognition System (VRS) used for improving phonological awareness and reading skills of preschool children. A quasi-experimental pre/post-test design with non-equivalent control group was used in third year of preschool education. The pupils $(n=18)$ were randomly assigned to an experimental or control group. The experimental group received seven training sessions on the use of VRS. The pre/post-test evaluation of phonological awareness and reading skills was carried out by LolEva, a test in a software format (Peralbo et al., 2015). Our results show a significant improvement in the experimental group in connection with phonemic and syllabic awareness. Improvements were also observed, although not statistically significant, in reading skills.
\end{abstract}

Keywords: voice recognition systems, pre-school education, learning to read, phonological awareness

Resumen

El objetivo principal de esta investigación es analizar los efectos de un sistema de reconocimiento de voz (SRV) utilizado para mejorar la conciencia fonológica y las habilidades lectoras de niños en edad preescolar. Se utilizó un diseño cuasi experimental pre/post-test con grupo control no equivalente en tercero de educación preescolar. Los alumnos $(n=18)$ fueron asignados aleatoriamente a un grupo experimental o control. El grupo experimental fue entrenado en el uso del SRV. La evaluación pre/post-test de conciencia fonológica y habilidades de lectura se llevó a cabo a través de la prueba informatizada LolEva (Peralbo et al., 2015). Nuestros resultados muestran una mejora significativa en el grupo experimental en conciencia fonémica y silábica. También se observaron mejoras, aunque no estadísticamente significativas, en las habilidades de lectura.

Palabras clave: sistemas de reconocimiento de voz, la educación pre-escolar, aprendiendo a leer, conciencia fonológica

This paper presents the findings of a quasi-experimental research whose aim has been to verify whether the use of a Voice Recognition System (VRS, from now on) has significant effects on the development of phonological awareness as well as on the initial reading skills in fiveyear-old children.

Learning and teaching how to read is one of the most important achievements which occur in the school context.

Correspondence concerning this article should be addressed to: Manuel Peralbo-Uzquiano, Department of Developmental and Educational Psychology. Campus de Elviña s/n, 15071, A Coruña (Spain). E-mail: man correspondence concerning this article should be addressed touel.peralbo@udc.es 
In this literacy teaching task, phonological awareness plays an essential role when learning how to read (Alegría, 2006; Nithart et al., 2010), yet acquiring it usually requires educational support (Defior, 2008; Mayor and Zubiauz, 2011). Nowadays, we know the different levels involved in developing it and also how to help children overcome the difficulties they are faced with when applying it to the different segmentation levels of a given word. Moreover, it is evident that those children who obtain a greater degree of phonological awareness in their oral language have a better chance to learn to read and write (Carroll, Snowling, Stevenson, and Hulme, 2003).

As Coltheart (1978) pointed out in his dual-route model, phonological mediation occurs during the first years of reading and it is therefore essential for teachers to have at their disposal tasks which allow them to further it as part of the day-to-day activities they carry out with their pupils in the classroom. The intervention procedure we have designed is one of the many existing options to help consolidate this learning.

During these last few years, new technologies have been incorporated into the literacy learning programmes as a way to improve classroom interaction and motivate children, about tasks which are not always easy to tackle (Godwin-Jones, 2009; Tunmer, 2008). However, as MacArthur, Ferretti, Okoli and Cavalier (2001) pointed out in their meta-analysis of literature on the use of technology to teach slightly disabled pupils how to read and write published between 1985 and 2000, the studies undertaken in this field do not always offer the necessary methodological consistency and, even though they appear to be efficient where lexical access is concerned, they do create additional needs. Nonetheless, new technologies arouse great expectations because of their compensation effect, in particular for those who are somehow disabled in terms of speaking, writing, associating, pointing and so on.

In the case of phonological awareness, the teaching nature of the tasks employed can sometimes cause them to be distanced from the natural use of language, which is typical of spontaneous communication contexts, and technology may help to place these tasks in as interactive a context as possible. Hatcher, Hulme and Ellis (1994) also point out the importance of the joint work done on phonology and reading by comparing the effects of different training programmes on the ability of seven-yearolds with reading difficulties to perform both of these skills. For them, the most efficient way to improve reading skills involves integrating the training in phonological skills into reading acquisition, as treating them separately (reading and phonology) is less effective.

Writing with VRS may be a task which comprises a great part of these interactive features. This technology has been used for language teaching (Chiu, Liou, and Yeh, 2007; Liaw, 2014), as well as in the sphere of special educational needs (Abad et al., 2013; Koester, 2001; Mader, 2008) and likewise in the field of language and communication disorders (Bruce, Edmundson, and Coleman, 2003; Caute and Woolf, 2016; Ferrier, Shane, Ballard, Carpenter, and Benoit, 1995; Hux, RankinErickson, Manasse, and Lauritzen, 2000; Miles, Martin, and Owen, 1998).

Using a VRS programme as a writing tool means inverting the usual reading process during the initial stages (as shown in Figure 1) regardless of the learning methods employed (Barreto, 2012; Fernández-Amado, Peralbo, and Mayor, 2005). It involves generating the idea first, then articulating it clearly, seeing it in writing and reading it.

In the word recognition process, the software can make lexicalization mistakes so that the "dictated" word does not correspond to the one transcribed on the screen (by the VRS). That is when educational intervention becomes possible and when the possibility to work on the phonological awareness becomes more evident than ever, regardless if the lexical or phonological way is being used to access the meaning of a written word (Patterson and Shewell, 1987).

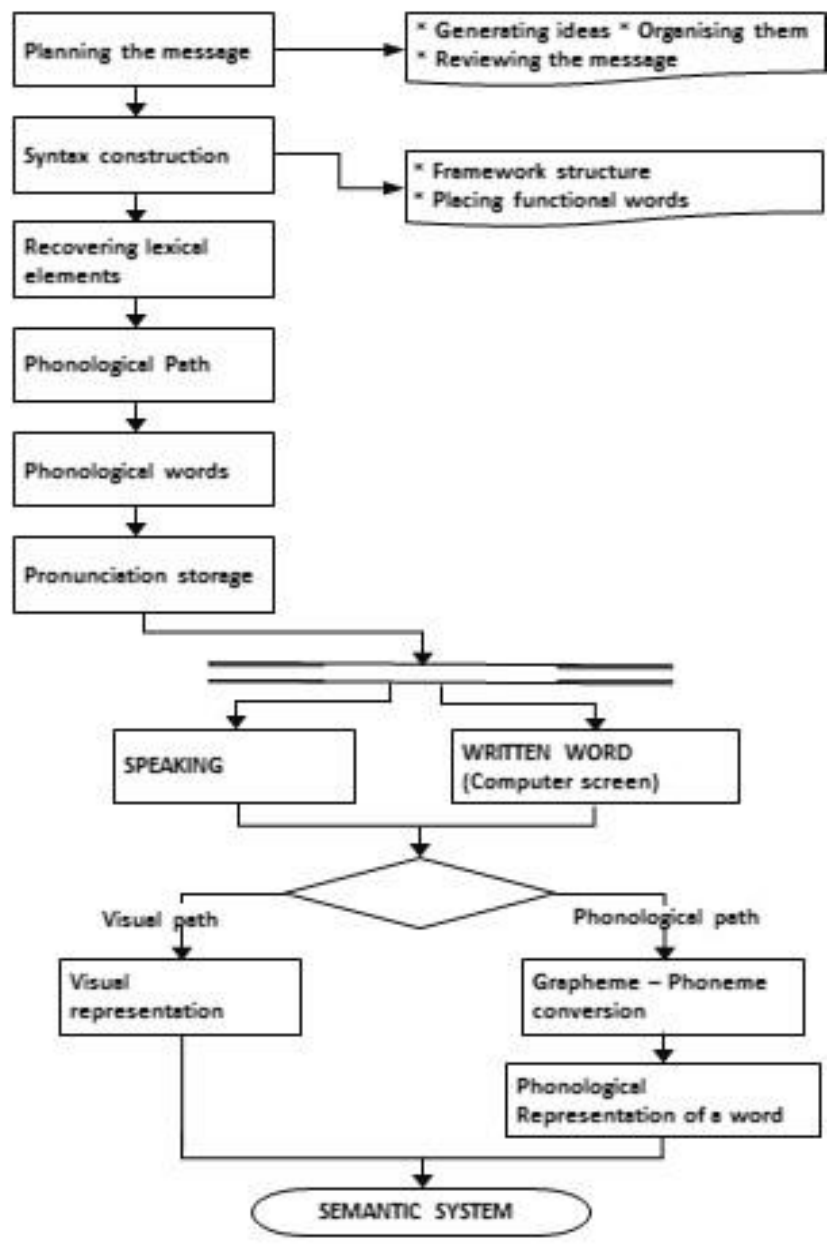

Figure 1. Flowchart representing the processes triggered by the VRS in the experimental situation. 
The fact that the VRS only produces existing words is highly useful from an educational point of view, since it works on reading acquisition through the lexical path.

The mistakes found in the words that are transcribed (e.g. "to" instead of "too") thus lead to the need for the pupil or the teacher to intervene to correct them, thereby inducing phonological awareness tasks which refer to manipulating the linguistic segments of rhyme, syllable and phoneme (Castles and Coltheart, 2004).

As Barreto (2012) points out it is important to consider that for the VRS to have any effect on the learning of writing, children must have overcome the stage at which they believe the graphic signs have not been produced by them, but by the adult or the computer itself . From there, they realize the writing is the result of their oral activity, although they cannot identify the meaning of what is written, to shortly after, understand that this meaning corresponds to the idea they wanted to communicate.

Taking into account what has been put forth so far, our objective has been to check the effect of the VRS as a possible segmentation strategy inducing tool within the framework of phonological awareness activities and, consequently, to verify its repercussion on some of the skills involved in reading acquisition in five-year-old children in preschool education. Introducing the VRS is expected to lead to significant improvements in rhyme, syllable and phoneme tasks, as well as in those tasks involving letter recognition and the reading of regular, irregular (visual path) and pseudo-words (phonological path).

\section{Method}

\section{Participants}

The sample was formed by 26 five-year-old pupils attending to year 3 of Spanish Preschool Education who were randomly divided into an experimental group and a control group. With the purpose that both groups were comparable, it was established as an exclusion criterion not to get a total score less or greater than 1.5 standard deviations in LolEva (a computer application designed to evaluate phonological awareness and reading skills; (Peralbo et al., 2015)). This allows to homogenize the sample in phonological awareness and early reading competence. This accounts for the different number of people in the two groups. The EG was made up of 7 pupils and the $\mathrm{CG}$ of 11 pupils. Both groups were considered to be comparable to each other, as they did not differ significantly in the phonological awareness and reading competence pre-test measures (Tables 1 and 2).

\section{Design}

The study was conducted using a quasi-experimental pre/post-test design with non-equivalent control group. Since at this level significant effects of instruction that can be mistaken for treatment effects are produced, we chose to focus the study on a single classroom assuming that this leads to a design with small $\mathrm{n}$. Thus, however, contamination of the style, the method or the teaching pace that different teachers might introduce was avoided. On the other hand, VRS requires individual treatment outside the classroom, therefore those who use it should be absent from class during treatment sessions. This means that even trying that VRS activities and activities in the classroom are similar, there can never be ensured a full equivalence between the children in the control and the treatment group In addition, working with preschool speech technology has technical complications that hinder the use of large samples, especially when exclusion criteria are set, as in this study, to ensure comparability of subjects. Moreover there is the need for all participants to receive treatment sessions at comparable times of the year, since the evolution of the studied skills is fast during the third year of preschool. Thus, two groups were formed in a preschool classroom of third year at a private school that was chosen following criteria accessibility. Within the classroom the 26 students were randomly assigned to the treatment group and the control group. The first (EG) was exposed to a teaching programme by means of the VRS, the second (CG) performed ordinary classrooms tasks during the same period of time.

\section{Instruments}

A computer application called LolEva (Peralbo et al., 2015) was used to evaluate phonological awareness and reading skills. This test consists of two protocols aimed at evaluating - (1) phonological awareness (PA) and (2) early reading competence $(\mathrm{RC})$. Within the first group there are seven sub-tests considering the levels of rhyme, syllable and phoneme in different tasks focusing on identifying adding and omitting syllable or phoneme segments, at the beginning and at the end of a word. The second protocol evaluates different degrees of letter recognition - capital and lower-case letters - as well as word reading - regular, irregular and pseudo-words. In the study published by Fernández-Amado, Peralbo and Mayor (2005) a detailed description of each task and the selection criteria used for the different items can be seen. The internal consistency of the test is 0.94 for the phonological awareness subscale and 0.92 for early reading skills subscale (Peralbo et al., 2015).

Recognising rhyme: identifying which drawing out of three does not rhyme with the other two.

Identifying syllables (beginning/end): identifying which drawing ends (or begins) with the same syllable as the model (five items for the beginning and five for the end). Every child is given four drawings each (one model and three which make up the options which the children are to choose from).

Adding syllables (beginning/end): saying what word is formed after adding a syllable at the beginning or the end of the model word (five items for the beginning and five 
ones for the end). In each one, three-syllable words are used.

Omitting syllables (beginning/end): saying what word is formed after removing a syllable at the beginning or the end of the model word (five items for the beginning and five ones for the end). All of the selected words have three syllables.

Identifying phonemes (beginning/end): identifying which drawing out of three begins (or ends) the same way as the model (five items for the beginning and five for the end).

Adding phonemes: saying what word is formed after adding a sound (phoneme) at the beginning or the end of the model word (five items for the beginning and five for the end).

Omitting phonemes: saying what word is formed after taking away a sound (phoneme) at the beginning or the end of the model word (five items for the beginning and five for the end).

Identifying capital letters: reading 29 capital letters aloud.

Identifying lower-case letters: reading 29 lower-case letters aloud.

Reading regular words: reading ten regular words, i.e. ones that are composed of direct phonemes those which to which one and only one grapheme correspond and vice versa (/m/, /s/, /t/, /n/, and so forth).

Reading irregular words: reading ten irregular words, i.e. ones that have one or more exceptional graphophonemes. Such phonemes correspond to several graphemes $(/ \mathrm{b} /, / \mathrm{j} /, / \mathrm{z} /, / \mathrm{k} /, / \mathrm{rr})$ and the graphemes $(/ \mathrm{r} /, / \mathrm{c} /$, $/ \mathrm{g} /$ ) of these words correspond to several phonemes.

Reading pseudo-words: reading ten pseudo-words which were constructed based on the words which make up the regular words questionnaire, either by changing the order of the syllables or the letters or by adding/omitting a letter.

This paper shows the data reflecting the number of correct answers for each task.

\section{Procedure}

The pre/post-test evaluations were carried out individually for a month.

The pupils underwent the Dragon Naturally Speaking $®$ VRS training phase in a first session, before starting to work with the experimental group. It is a matter of getting the VRS to recognise the differential voice features of each child. In order to do so, the teacher asks them to say after him/her (reading the text shown on a screen). After the initial training, all the sessions have the same outline. To begin with, the child says the date, their name and age and the VRS transcribes it to the screen. The teacher subsequently starts a conversation with the child asking them to tell the computer something. This task, furthermore, involves having the child review the words that appear on the screen. The phonological awareness training arises when the VRS writes something different to what the child actually said. That is when the instructor suggests that the child should compare what they said to what they can actually see in writing on the screen, thereby inducing the child to perform a (syllable or phonemic) segmentation task needed to identify the word which the computer did not transcribe correctly. This process ends when the child repeats the word to the computer, articulates it clearly and it is written correctly on the screen.

With the aim of ensuring that the sessions followed their course adequately and that the sequence of tasks performed was measured, each training session was registered and subsequently transcribed onto a control template on which the following information was recorded: the pupil's linguistic production, their self-corrections, the segmentations tasks carried out, as well as the help given.

While every child in the experimental group performed these tasks individually outside the classroom, the rest of their classmates, from the experimental and the control groups alike, went on with their usual everyday classroom activities.

\section{Results}

The statistical analysis was undertaken by comparing the performance achieved by the experimental and the control groups in pre and post-test, by means of the MannWhitney U SPSS v.19 test for two independent samples. In order to analyze the control group and the experimental group's evolution throughout the course independently, their results at pre-test and post-test were independently compared using the sign test with Wilcoxon rank. The selected statistics are, in both cases, non-parametric. The reason has to do with the small sample size and the inability to ensure that the requirements for the application of parametric tests are met.

\section{Phonological Awareness}

The results obtained show no differences among Control and Experimental groups in pre-test (see Table 1, Figures 2 and 3). So, the EG reached a significantly higher achievement level than the $\mathrm{CG}$ in the following skills of the post-test:

\section{Syllable awareness.}

The findings show that the EG achieved a significant improvement in: Adding an initial syllable, Adding a final syllable and Omitting an initial syllable. The Sum of adding syllables is also significant in post-test.

\section{Phonemic awareness.}

The results show that the EG achieved a significant improvement in: Adding an initial phoneme and Adding a final phoneme. So, the Sum of adding phoneme is also significant in post-test. 
Regarding the score on all the phonological awareness tests (um all phonological tasks), the results indicate that both groups were comparable at pre-test, whereas significant differences between them occur in the post-test (see Table 1, Figure 5).

Table 1

Pre-post intergroup differences in phonological awareness (CG: $n=11 ; E G: n=7$ )

\begin{tabular}{|c|c|c|c|c|c|c|c|c|c|}
\hline \multirow{2}{*}{ Phonological awareness } & \multirow[b]{2}{*}{ Phase } & \multicolumn{2}{|c|}{ Mean Ranks } & \multirow[b]{2}{*}{$U$} & \multirow{2}{*}{ Phonological awareness } & \multicolumn{4}{|c|}{ Mean Ranks } \\
\hline & & $\mathrm{CG}$ & EG & & & Phase & CG & EG & $U$ \\
\hline \multirow{2}{*}{ Rhyme } & Pre & 8.50 & 11.07 & 27.500 & \multirow{2}{*}{ Sum identifying phoneme } & Pre & 9.73 & 9.14 & 36.000 \\
\hline & Post & 8.23 & 11.50 & 24.500 & & Post & 7.82 & 12.14 & 20.000 \\
\hline \multirow{2}{*}{ Sum identifying syllables } & Pre & 10.59 & 7.79 & 26.500 & \multirow{2}{*}{ Beginning } & Pre & 10.41 & 8.07 & 28.500 \\
\hline & Post & 8.18 & 11.57 & 24.000 & & Post & 8.23 & 11.50 & 24.500 \\
\hline \multirow{2}{*}{ Beginning } & Pre & 10.14 & 8.50 & 31.500 & \multirow{2}{*}{ End } & Pre & 9.77 & 9.07 & 35.500 \\
\hline & Post & 7.95 & 11.93 & 21.500 & & Post & 8.14 & 11.64 & 23.500 \\
\hline \multirow{2}{*}{ End } & Pre & 10.41 & 8.07 & 28.500 & \multirow{2}{*}{ Sum adding phoneme } & Pre & 7.73 & 12.29 & 19.000 \\
\hline & Post & 8.73 & 10.71 & 30.000 & & Post & 6.27 & 14.57 & $3.000 * * *$ \\
\hline \multirow{2}{*}{ Sum adding syllables } & Pre & 8.36 & 11.29 & 26.000 & \multirow{2}{*}{ Beginning } & Pre & 9.05 & 10.21 & 33.500 \\
\hline & Post & 6.09 & 14.86 & $1.000 * * *$ & & Post & 6.32 & 14.50 & 3.500 \\
\hline \multirow{2}{*}{ Beginning } & Pre & 8.64 & 10.86 & 29.000 & \multirow{2}{*}{ End } & Pre & 7.77 & 12.21 & 19.500 \\
\hline & Post & 6.18 & 14.71 & $2.000 * * *$ & & Post & 7.36 & 12.86 & 15.000 \\
\hline \multirow{2}{*}{ End } & Pre & 8.50 & 11.07 & 27.500 & \multirow{2}{*}{ Sum omitting phoneme } & Pre & 10.55 & 7.86 & 27.000 \\
\hline & Post & 6.73 & 13.86 & $8.000^{* *}$ & & Post & 7.82 & 12.14 & 20.000 \\
\hline \multirow{2}{*}{ Sum omitting syllables } & Pre & 8.50 & 11.07 & 27.500 & \multirow{2}{*}{ Beginning } & Pre & 10.23 & 8.36 & 30.500 \\
\hline & Post & 7.09 & 13.29 & $12.000 *$ & & Post & 7.73 & 12.29 & 19.000 \\
\hline \multirow{2}{*}{ Beginning } & Pre & 8.45 & 11.14 & 27.000 & \multirow{2}{*}{ End } & Pre & 10.45 & 8.00 & 28.000 \\
\hline & Post & 6.91 & 13.57 & $10.000 * *$ & & Post & 8.86 & 10.50 & 31.500 \\
\hline \multirow{2}{*}{ End } & Pre & 9.36 & 9.71 & 37.000 & \multirow{2}{*}{$\begin{array}{l}\text { Sum all phonological } \\
\text { awareness tasks }\end{array}$} & Pre & 9.27 & 9.86 & 36.000 \\
\hline & Post & 8.55 & 11.00 & 28.000 & & Post & 6.27 & 14.57 & 3.000 \\
\hline
\end{tabular}

$* p<.05 ; * * p<.01 ; * * * p<.001$

¿G Pretest $\square$ CG Postest $\square$ EG Pretest $\quad$ EG Postest

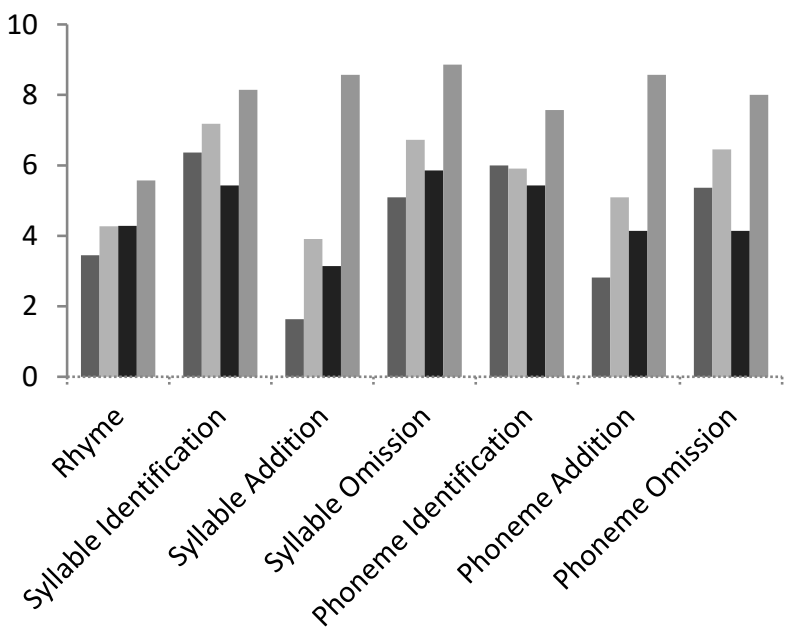

Figure 2. Results in phonological awareness tasks regardless of initial or final segment.

\section{Reading Competence}

As in phonological awareness tasks, there were no significant differences between groups in the pre-test. However, in this case the effects of treatment, although being remarkable in some cases, are not statistically significant in the post-test, (see Table 2 and Figures 4 and 5).
The findings show that the EG achieved a significant improvement in all of the reading tests that involved lexical access (reading regular, irregular and pseudo-words). In the case of reading uppercase and lowercase letters, there are no differences between the two groups because of a ceiling effect in this reading process (especially in the case of capital letters).

Table 2

Pre-Post Intergroup Differences in Early Reading Skills (CG: $n=11 ; E G: n=7$ )

\begin{tabular}{|c|c|c|c|c|}
\hline \multirow{2}{*}{ Early Reading Skills } & \multirow[b]{2}{*}{ Phase } & \multicolumn{2}{|c|}{ Mean Ranks } & \multirow[b]{2}{*}{$U$} \\
\hline & & CG & EG & \\
\hline \multirow{2}{*}{ Identifying capital letters } & pre & 9.95 & 8.79 & 33.500 \\
\hline & post & 9.95 & 8.79 & 33.500 \\
\hline \multirow{2}{*}{ Identifying lower case letters } & pre & 9.68 & 9.21 & 36.500 \\
\hline & post & 9.09 & 10.14 & 34.000 \\
\hline \multirow{2}{*}{ Reading regular words } & pre & 9.41 & 9.64 & 37.500 \\
\hline & post & 8.32 & 11.36 & 25.500 \\
\hline \multirow{2}{*}{ Reading irregular words } & pre & 9.59 & 9.36 & 37.500 \\
\hline & post & 8.18 & 11.57 & 24.000 \\
\hline \multirow{2}{*}{ Reading pseudo- words } & pre & 10.55 & 7.86 & 27.000 \\
\hline & post & 8.32 & 11.36 & 25.500 \\
\hline \multirow{2}{*}{ Sum all reading tasks } & pre & 10.00 & 8.71 & 33.000 \\
\hline & post & 8.45 & 11.14 & 27.000 \\
\hline \multirow{2}{*}{ LolEva Total score } & pre & 9.23 & 9.93 & 35.500 \\
\hline & post & 6.45 & 14.29 & $5.000 *$ \\
\hline
\end{tabular}

$* p<.01$ 
aG Pretest $\square$ CG Postest $\quad$ EG Pretest $\quad$ EG Postest

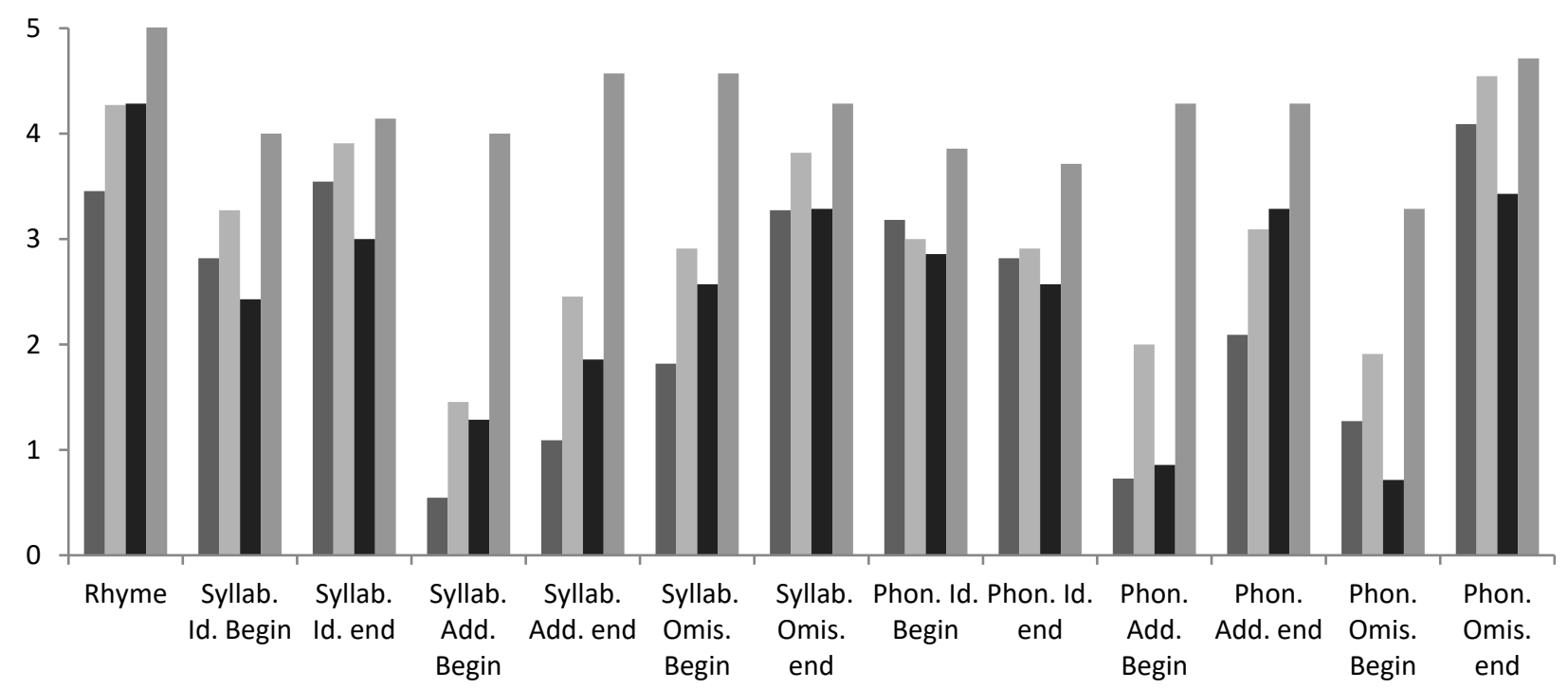

Figure 3. Detailed results of the tests of phonological awareness according to the initial or final position of the affected segment.

$\square$ CG Pretest $\square$ CG Postest $\square$ EG Pretest $\quad$ EG Postest

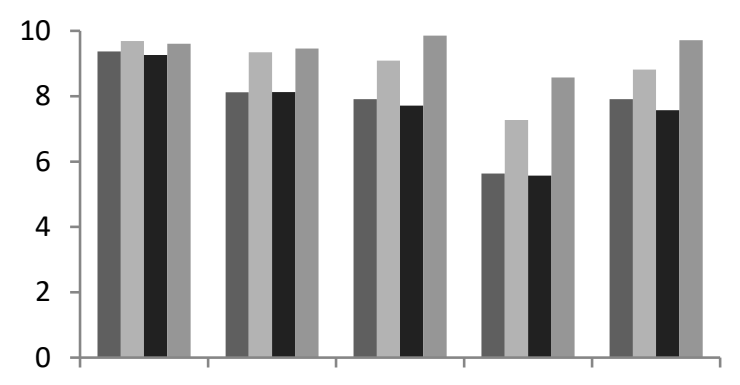

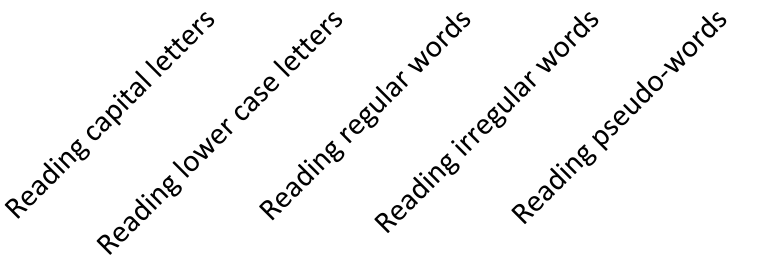

Figure 4. Results of all reading tasks.

After checking the differences between the two groups before and after treatment, we analysed the evolution that everyone had throughout the school year during which the treatment was implemented. We can consider the changes that have occurred in the control group as a reference to understand how the introduction of treatment sessions in the experimental group could affect its evolution. As seen in Table 3, the improvements in the control group occur as a result of schooling in: adding syllable at the end of the word, omission of syllable at the beginning of the word and adding phoneme at the beginning of the word. In the experimental group, however, the changes are produced in syllable identification at the beginning of the word, adding syllable at the beginning, adding syllable at the end of the word, omission of syllable at the beginning of the word, phoneme identification at the beginning of the word, adding phoneme at the beginning, adding phoneme at the end of the word, omission of phoneme at the beginning and end of the word. Nevertheless, in both groups, the total profits in phonological awareness throughout the evaluated year period are positive and significant.

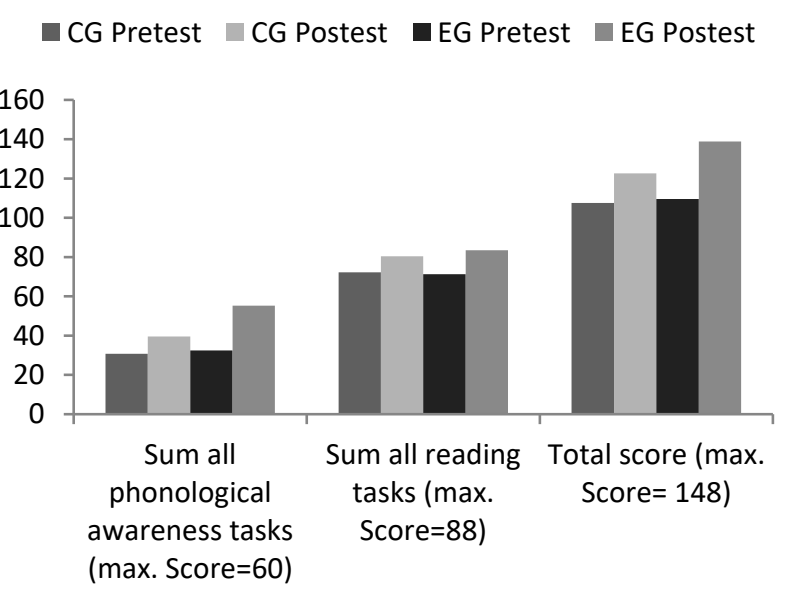

Figure 5. Changes between Pre-test and Post-test considering the overall results in phonological awareness, reading and total score on the test (LolEva). 
Table 3

Pre-post intragroup differences in phonological awareness and early reading skills

\begin{tabular}{lcc}
\hline & CG pre-post & EG pre-post \\
& $\mathrm{Z}$ & $\mathrm{Z}$ \\
\hline Rhyme & -1.449 & -1.841 \\
\hline Sum identifying syllables & -1.278 & $-2.060^{*}$ \\
Beginning & -1.155 & $-2.232^{*}$ \\
End & -.973 & -1.715 \\
\hline Sum adding syllables & $-2.680^{* *}$ & $-2.375^{*}$ \\
Beginning & -1.781 & $-2.214^{*}$ \\
End & $-2.172^{*}$ & $-2.232^{*}$ \\
\hline Sum omitting syllables & $-2.219^{*}$ & $-2.384^{*}$ \\
Beginning & $-1.997^{*}$ & $-2.032^{*}$ \\
End & -1.613 & -1.725 \\
\hline Sum identifying phoneme & -.183 & $-2.388^{*}$ \\
Beginning & -.425 & $-2.070^{*}$ \\
End & -.306 & -1.807 \\
\hline Sum adding phoneme & $-2.820^{* *}$ & $-2.379^{*}$ \\
Beginning & $-2.456^{*}$ & $-2.388^{*}$ \\
End & -1.872 & $-2.070^{*}$ \\
\hline Sum omitting phoneme & -1.736 & $-2.388^{*}$ \\
Beginning & -1.594 & $-2.220^{*}$ \\
End & -.905 & $-2.041^{*}$ \\
\hline Sum all phonological awareness. & $-2.941^{* *}$ & $-2.366^{*}$ \\
Tasks & & \\
Identifying capital letters & -1.710 & -1.725 \\
Identifying lower case letters & $-2.524^{*}$ & $-2.375^{*}$ \\
Reading regular words & $-2.050^{*}$ & -1.826 \\
Reading irregular words & $-2.459^{*}$ & $-2.388^{*}$ \\
Reading pseudo-words & $-2.126^{*}$ & $-2.456^{*}$ \\
Sum all reading tasks & $-2.807^{*}$ & $-2.375^{*}$ \\
LolEva total score & $-2.936^{* *}$ & $-2.371^{*}$ \\
\hline
\end{tabular}

$* p>.05 ; * * p<.01$

In the case of tasks related to reading, both groups improved significantly in all along the year (see Figure 4). The only exception occurs in the experimental group in the task of reading regular words, despite being his improvement in right answers higher than the control group ( $p$-value in this case was .068). In the case of reading letters assignments both groups reach the test ceiling, while in those assignments involving reading words this effect tends to occur in the experimental group. Also in the task of reading irregular words, which is more complex, is the experimental group that gets the best results.

In short, these findings confirm our first hypothesis: training with the VRS as well as being taught how to do the metaphonological tasks which are derived from those lead to an improvement in phonological awareness skills. Our second hypothesis is likewise confirmed: this type of teaching does result in an enhanced reading competence during its initial stages; and it more specifically improves performance as far as reading words and pseudo-words is concerned. This is so because the lexical and phonological paths providing access to the meaning of words are used in a more adequate and functional manner.

\section{Discussion}

The main objective of this paper is to verify whether the educational use of a VRS can help to improve the segmentation skills involved in the development of phonological awareness and the ones connected with Early Childhood Education children (five-year-old) learning how to read and write.

Generally speaking, our findings indicate that using the VRS helps to produce significant improvements, not only in terms of phonological awareness, but in where reading words is concerned. This advance is seen at virtually all levels of phonological awareness, yet it is particularly evident in those which involve analysing infrequent segments (omitting in an initial position) and linguistic segment synthesis (adding). This progress can most likely be accounted for by the fact that the present training stressed those skills which are usually the least taught ones in the field of ordinary pre-reading classroom activities.

On the other hand, the absence of significant differences between both groups in different tasks, can be due to a number of different reasons. In some cases, it may have something to do with the task being quite easy for fiveyear-olds (e.g. rhyme and letter recognition). In other cases, it may be owing to more complex cognitive requirements that the different segmental analysis tasks used entail; some of them would need more training sessions in order to achieve a significant differential effect.

The different degrees of complexity concerning the phonological awareness tasks has been analysed not only in Spanish (Jiménez and Ortiz, 1995), but in other languages too (Cossu, Shankweiler, Liberman, Katz, and Tola, 1988). In this respect, the levels of phonological awareness are established in accordance with the demands involved in the same tasks - linguistic code (segment), cognitive resource availability (attention and work memory) and the explicit level of requirement for the segmentation activity itself (task + the position of the segment).

According to that, our findings agree with previous ones and they reflect that there is an evolutionary course in phonological awareness. They also establish that syllable segmentation is easier to solve than the phonemic one (Carroll et al., 2003).

Our data also confirm that the position of the phonological segment in question in a given word causes an additional complexity. The positive effects of training on the capacity to manipulate the structure of the word with regard to the syllable especially show themselves, at this age, in the adding task (adding to the beginning or the end) and in the omission one (above all the initial one). The significant improvement achieved from training in the phoneme-related tasks is situated in the tasks connected with adding and omitting the initial phoneme, as well as in the one referring to identifying the final phoneme.

Thus, we can observe that the position of the unit to be manipulated in the word has an important effect. In our 
case, manipulating the final position units presents us with a different degree of complexity depending on the task and the segment being worked with. This variability, which has also been analysed in other studies where the training was systematic, rather than incidental, leads us to think about the need to value the conjugated effect which the unit to be manipulated (syllable/phoneme) together with the position of the segment (initial/final) and the type of task involved (identification, addition, omission).

Moreover, the procedure used has produced an improvement with regard to reading words (regular and irregular) and pseudo-words. This increase in the use of the phonological path allows us to reach the conclusion that the VRS generates an incidental training context. Depending on what type of transcription "error" is made, different metaphonological skills helping to analyse a given word are developed. This repeated practice results in developing greater competence in segmentation skills which will progressively permit reading more and more complex words.

Our findings also endorse the interest in working on phonology and reading jointly, as Hatcher, Hulme and Ellis (1994) among others pointed out. Interpreting the improvement achieved in both competences points to a "convergence" process which appears to be promoting the complementary development of the two paths, i.e. the lexical and phonological ones. They are both necessary in order to reach a balanced reading capacity. In this respect, the VRS constitutes an ideal procedure to offer activities capable of fomenting the articulation between oral and written language in pupils, providing them strategies guaranteeing progress during the first stages of reading. All of this evidently happens in a mediation context in which the school master/mistress helps the pupil identify what the task requires, while also giving the pupil a framework for what we call incidental learning, no matter what method is being used for learning to read.

Using the VRS as a support for reading/writing learning thus presents us with some advantages which we can summarise below. Firstly, it generates a context where meaning and comprehension precede oral expression and conversation in written text and where the message makes complete sense in the pupil's social context. Secondly, transforming the oral message into text helps to understand the notational value of the written signs, reusing the phonological path which gives access to the words systematically and since the automatic writing is followed by the visualisation of each word, whose meaning has previously been elaborated, the system makes it easier to work on reading comprehension. Thirdly, permanent reviewing practice in order to "compare" the degree of correspondence between oral production and the written word helps to develop the lexical path.

To conclude, the findings obtained in this study allow us to think of the possibility to improve in-classroom reading learning by means of using ICT, taking advantage of these technologies' flexibility to adapt ourselves to the individual characteristics of pupils who have reading learning difficulties, whether they are specific or of a broader nature.

Among the limitations of this work are those related to the difficulty to customize the voice recognition in preschool children who cannot read the evaluation texts and whose articulation does not always facilitate a suitable voice recognition. As Barreto (2012) points out, the implementation of speech technology facilitates the acquisition of literacy, but also introduces costs and complexities that should be taken into account. Technological research should help resolve these problems if a completely widespread use in education is intended.

Although the individual application of this technology is difficult to use in schools, more studies aimed at verify the different effect that VRS have on children with different levels of language development, or with different initial levels of phonological awareness development are necessary. To know what early ages are possible to reach with these systems is important for their educational and clinical use.

\section{References}

Abad, A., Pompili, A., Costa, A., Trancoso, I., Fonseca, J., Leal, G., . . . Martins, I. P. (2013). Automatic word naming recognition for an on-line aphasia treatment system. Computer Speech and Language, 27(6), 12351248. http://dx.doi.org/10.1016/j.csl.2012.10.003

Alegría, J. (2006). Por un enfoque psicolingüístico del aprendizaje de la lectura y sus dificultades-20 años después. [For a psycholinguistic approach to reading and learning difficulties, 20 years later] 29(1), 93-111. http://dx.doi.org/10.1174/021037006775380957

Barreto, M. (2012). Efectos de un programa de reconocimiento de voz en la adquisición de la escritura. una experiencia con niños entre 4 y 6 años. (Unpublished MA Thesis). University of Antioquia, Medellín (Colombia).

Bruce, C., Edmundson, A., \& Coleman, M. (2003). Writing with voice: An investigation of the use of a voice recognition system as a writing aid for a man with aphasia. International Journal of Language \& Communication Disorders, 38(2), 131-148. http:// dx.doi.org/10.1080/1368282021000048258

Carroll, J. M., Snowling, M. J., Stevenson, J., \& Hulme, C. (2003). The development of phonological awareness in preschool children. Developmental Psychology, 39(5), 913-923. http://dx.doi.org/10.1037/0012-1649.39.5.913

Castles, A., \& Coltheart, M. (2004). Is there a causal link from phonological awareness to success in learning to read? Cognition, 91, 77-91. http://dx.doi.org/10.1016/ S0010-0277(03)00164-1

Caute, A., \& Woolf, C. (2016). Using voice recognition software to improve communicative writing and social participation in an individual with severe acquired 
dysgraphia: An experimental single-case therapy study. Aphasiology, 30(2-3), 245-268. http://dx.doi.org/ 10.1080/02687038.2015.1041095

Chiu, T., Liou, H., \& Yeh, Y. (2007). A study of web-based oral activities enhanced by automatic speech recognition for EFL college learning. Computer Assisted Language Learning, 20(3), 209-233. http:// dx.doi.org/10.1080/09588220701489374

Coltheart, M. (1978). Lexical access in simple reading tasks. In G. Underwood (Ed.), Strategies of information processing (pp. 151-216). London: Academic Press.

Cossu, G., Shankweiler, D., Liberman, I., Katz, L., \& Tola, G. (1988). Awareness of phonological segments and reading ability in italian children. Applied Psycholinguistics, 9, 1-16. http://dx.doi.org/10.1017/ S0142716400000424

Defior, S. (2008). ¿Cómo facilitar el aprendizaje inicial de la lectoescritura? papel de las habilidades fonológicas. Infancia Y Aprendizaje, 31(3), 333-345. http://dx.doi. org/10.1174/021037008785702983

Fernández-Amado, L., Peralbo, M., \& Mayor, M. A. (2005). Aplicaciones del software de reconocimiento de voz sobre el aprendizaje de la lectoescritura: Un estudio preliminar. In M. M. Mayor, B. Zubiauz \& E. DíezVilloria (Eds.), Estudios sobre la adquisición del lenguaje [Applications of speech recognition software to literacy learning: a preliminary study] (pp. 787-802). Salamanca: Ediciones Universidad de Salamanca.

Ferrier, L. J., Shane, H. C., Ballard, H. F., Carpenter, T., \& Benoit, A. (1995). Dysarthric speakers' intelligibility and speech characteristics in relation to computer speech recognition. AAC: Augmentative and Alternative Communication, 11(3), 165-174. http://dx.doi.org/ 10.1080/07434619512331277289

Godwin-Jones, R. (2009). Emerging technologies. speech tools and technologies. Language Learning \& Technology, 13(3), 4-11. http://llt.msu.edu/vol13num3/ emerging.pdf

Hatcher, P., Hulme, C., \& Ellis, A. W. (1994). Ameliorating early reading failure by integrating the teaching of reading and phonological skills: The phonological linkage hypothesis. Child Development, 65, 41-57. http://dx.doi.org/10.1111/j.1467-8624.1994. tb00733.x

Hux, K., Rankin-Erickson, J., Manasse, N., \& Lauritzen, E. (2000). Accuracy of three speech recognition systems: Case study of dysarthric speech. AAC: Augmentative and Alternative Communication, 16(3), 186-196. http://dx.doi.org/10.1080/07434610012331279044
Jiménez, J. E., \& Ortiz, M. R. (1995). Conciencia fonológica y aprendizaje de la lectura. Teoría, evaluación e intervención [Phonological awareness and learning to read. Theory, Assessment and Intervention]. Madrid (Spain): Síntesis.

Koester, H. H. (2001). User performance with speech recognition: A literature review. Assistive Technology, 13(2), 116-130.

Liaw, M. (2014). The affordance of speech recognition technology for EFL learning in an elementary school setting. Innovation in Language Learning and Teaching, 8(1), 79-93.

MacArthur, C. A., Ferretti, R. P., Okolo, C. M., \& Cavalier, A. R. (2001). Technology applications for students with literacy problems: A critical review. The Elementary School Journal, 101(3, Special Issue: Instructional Interventions for Students with Learning Disabilities), 273-301. http://dx.doi.org/10.1086/499669

Mader, C. L. (2008). The effects of speech recognition technology on the writing skills and attitudes of adolescents with learning disabilities Available from PsycINFO. (621736536; 2008-99130-469).

Mayor, M. A., \& Zubiauz, B. (2011). Programa de intervención LOLE del lenguaje oral al lenguaje escrito [LOLE intervention program. From oral to written language]. Madrid (Spain): TEA Ediciones.

Miles, M., Martin, D., \& Owen, J. (1998). A pilot study into the effects of using voice dictation with secondary dyslexic pupils. Exeter: Devon LEA.

Nithart, C., Demont, E., Metz-Lutz, M. N., Majerus, S., Poncelet, M., \& Leybaert, J. (2010). Early contribution of phonological awareness and later influence of phonological memory throughout reading acquisition. Journal of Research in Reading, 34(3), 346-363. http://dx.doi.org/10.1111/j.1467-9817.2009.01427.x

Patterson, K., \& Shewell, C. (1987). Speak and spell: Dissociations and word-class effects. In M. Coltheart, G. Sartori \& R. Job (Eds.), The cognitive neuropsychology of language (pp. 273-294). London: Lawrence Erlbaum.

Peralbo, M., Mayor, M. Á, Zubiauz, B., Risso, A., Fernández-Amado, M. L., \& Tuñas, A. (2015). The loleva oral and written language test: Psychometric properties. The Spanish Journal of Psychology, 18. http://dx.doi.org/10.1017/sjp.2015.15

Tunmer, W. E. (2008). Recent developments in reading intervention research: Introduction to the special issue. Reading and Writing, 21(4), 299-316. http://dx.doi.org/ 10.1007/s11145-007-9108-4
Fecha de recepción: 14 de octubre de 2016. Fecha de revisión: 23 de noviembre de 2016. Fecha de aceptación: 26 de noviembre de 2016. Fecha de publicación: 1 de diciembre de 2016. 